\title{
Analisis Pengetahuan Lingkungan dan Sikap Peduli Lingkungan terhadap Ekosistem Sungai Berbasis Kearifan Lokal Lubuk Larangan di Desa Tambangan Jae Kecamatan Tambangan Kabupaten Madina
}

\author{
Nur Hidayah $^{1}$ Syarifuddin $^{2}$ Tumiur Gultom ${ }^{2}$ \\ ${ }^{1}$ Guru Biologi di SMP IT Al-Hijrah Deli Serdang \\ ${ }^{2}$ Program Studi Pendidikan Bilogi, Pascasarjana Universitas Negeri Medan, Sumatera Utara, Indonesia \\ Email: nurhidayahlubis@ rocketmail.com
}

\begin{abstract}
This research aims to: Find out the level of students and communities environmental knowledge towards river ecosystem based local wisdom (in)* lubuk larangan (part of the river which the fishes cannot be taken until the certain time)* basedon the level of education; Determine the level of environmental knowledge of students and communities towards river ecosystem based local wisdom lubuk larangan. The research used a quantitative descriptive research. The research sample as many as 158 students and 50 communities who live in Tambangan village Tambangan District, Madina Regency. The instrument used in this research was a questionnaire. Data analysis technique used Friedman-test. The final conclusion of the research: The level of education and location of the school influenced the level of knowledge about the environment of students based on local wisdom lubuk larangan basedon the level of education. The average of adult's knowledge was higher than High School, Junior High and Elementary School students.
\end{abstract}

KeyWords: Eenvironmental knowledge, environmental attitude.river ecosystem, local wisdom, lubuk larangan.

\section{PENDAHULUAN}

Seiring dengan berkembangnya aktivitas masyarakat di sekitar bantaran sungai tentunya akan berpengaruh terhadap kualitas air sungai, karena limbah yang dihasilkan dari aktivitas masyarakat tersebut bila dibuang langsung ke perairan sungai bila melebihi kemampuan sungai untuk membersihkan diri sendiri (self purification), maka timbul permasalahan yang serius yaitu pencemaran perairan, sehingga berpengaruh negatif terhadap kehidupan biota perairan dan kesehatan masyarakat yang memanfaatkan air sungai tersebut (Kasry, 2005).

Yunus (2005) menyatakan bahwa terbatasnya upaya pengendalian pencemaran air diperparah dengan rendahnya kesadaran masyarakat terhadap lingkungan serta kurangnya penegakan hukum bagi pelanggar pencemaran lingkungan. Krisis dan pencemaran air yang terjadi tersebut tidak terlepas dari pengetahuan, sikap, perilaku dan peranserta masyarakat yang buruk dalam memanfaatkan dan mengolah sumber daya air secara berkelanjutan. Beberapa daerah yang ada di Indonesia mempunyai aturan tersendiri untuk melestarikan lingkungannya yang sudah melekat dalam diri masyarakat tersebut secara turun temurun.

Kesadaran terhadap lingkungan hidup merupakan aspek yang penting dalam pengelolaan lingkungan hidup karena kesadaran terhadap lingkungan hidup merupakan bentuk kepedulian seseorang terhadap kualitas lingkungan, sehingga muncul berbagai aksi menentang kebijaksanaan yang tidak berwawasan lingkungan (Swan dan Stapp, 1974). Sedangkan menurut Krech and Crutcfield (1985) menyatakan bahwa tingkat kesadaran masyarakat terhadap lingkungan terjadi sebagai akibat berkembangnya pemahaman terhadap lingkungan itu sendiri ataupun akibat terjadinya perubahan kebutuhan nilai-nilai yang dianut, sikap dan karakteristik individu. Menurut Iskandar (2003) terdapat keterkaitan yang sangat erat antara pandangan manusia terhadap kelestarian lingkungannya. Selanjutnya dikatakan pula bahwa pandangan manusia tersebut tergantung dari pengetahuan dan 
pengalaman yang diperolehnya, serta norma-norma yang terdapat di sekitar lingkungan tempatnya berada.

Pendidikan lingkungan hidup tidak hanya diberikan pada kegiatan formal saja, akan tetapi dapat juga diberikan pada jalur non-formal seperti kegiatan Pramuka, Pecinta Alam, Palang Merah Remaja, dan Prokasih serta pembinaan dan pelatihan lingkungan di luar sekolah formal. Hal tersebut dikuatkan dalam Deklarasi Cimanggis (2007) poin kedua bahwa salah satu cara meningkatkan pendidikan tentang alam dan lingkungan, melalui jalur formal (SD, SMP, dan SMA) maupun jalur nonformal untuk meningkatkan kecintaan masyarakat terhadap alam, lingkungan dan orang lain.

Pendidikan lingkungan hidup menurut konvensi UNESCO (1997) dalam Sudaryanti (2009), merupakan suatu proses yang bertujuan untuk menciptakan suatu masyarakat dunia yang memiliki kepedulian terhadap lingkungan dan masalah-masalah yang terkait di dalamnya serta memiliki pengetahuan, motivasi, komitmen, dan keterampilan untuk bekerja, baik secara perorangan maupun kolektif dalam mencari alternatif atau memberi solusi terhadap permasalahan lingkungan hidup yang ada sekarang dan untuk menghindari timbulnya masalah-masalah lingkungan hidup yang baru. Dari penjelasan tersebut dapat ditarik pengertian bahwasanya pendidikan lingkungan hidup selayaknya didapatkan oleh setiap lapisan masyarakat, sehingga akan timbul pemahaman yang baik seterusnya akan tumbuh kesadaran dalam pelestarian fungsi lingkungan hidup di sekitarnya.

Pemahaman tentang dimensi ini akan membentuk atau menjadi tanda penting tentang esensi dan makna dari pengalaman didasarkan pada budaya Indonesia. Akibatnya, ada kebutuhan untuk membentuk kurikulum yang benar, sebagai faktor penting untuk mencapai inspirasi pendidikan untuk memajukan bangsa. Oleh karena itu, untuk menempatkan paradigma budaya dalam konteks pendidikan nasional, penting untuk meneliti kearifan lokal. Kosmaryandi (dalam Parwati, dkk., 2012) kekayaan pengetahuan masyarakat lokal di Indonesia sudah berkembang dalam jangka waktu yang panjang sejalan dengan perkembangan peradaban manusia. Proses perkembangan tersebut memunculkan banyak pengetahuan dan tata nilai tradisional yang dihasilkan dari proses adaptasi dengan lingkungannya. Sesuai dengan kebutuhan dasar manusia, salah satu bentuk pengetahuan tradisional yang berkembang adalah pengetahuan dalam pemanfaatan lahan, baik sebagai tempat tinggal maupun tempat untuk mencari atau memproduksi bahan makanannya.

Kearifan lokal merupakan salah satu warisan budaya yang ada di masyarakat (tradisional) dan secara turun-temurun dilaksanakan oleh masyarakat yang bersangkutan. Kearifan lokal tersebut umumnya berisi ajaran untuk memelihara dan memanfaatkan sumberdaya alam (hutan, tanah, dan air) secara berkelanjutan. Subak di Bali dan Sasi di Maluku merupakan contoh kearifan lokal yang masih dilaksanakan oleh masyarakat setempat dan mampu memelihara sumberdaya alam sehingga dapat memberikan penghidupan untuk masyarakat setempat secara berkelanjutan. Dari sisi lingkungan hidup keberadaan kearifan lokal sangat menguntungkan karena secara langsung atau pun tidak langsung sangat membantu dalam memelihara lingkungan serta mencegah terjadinya kerusakan lingkungan (Lampe dalam Parwati.,dkk 2012).

Kabupaten Madina sebagai bagian dari wilayah Provinsi Sumatera Utara yang didiami oleh mayoritas suku Mandailing juga memiliki kearifan lokal dalam pelestarian lingkungan. Kearifan lokal suku Mandailing pada dasarnya berasal dari budaya yang dikenal dengan petitih alam takambang manjadi guru.

Salah satu bentuk kearifan lokal yang dimiliki dan masih dikembangkan adalah lubuk larangan yang digunakan untuk melestarikan wilayah sungai dalam batasan tertentu dengan aturan tertentu. Adanya lubuk larangan tersebut baik disadari dan dipahami atau tidak merupakan sikap pelestarian ekosistem sungai. Salah satu 
daerah yang melestarikan lubuk larangan adalah masyarakat di Kecamatan Tambangan Kabupaten Madina, dengan nama Lubuk Larangan Anak Yatim.

Berdasarkan uraian permasalahan di atas, maka dipandang perlu untuk melakukan suatu penelitian pengetahuan lingkungan dan sikap peduli lingkungan disekitar lubuk larangan. Penelitian ini dilaksanakan pada bulan Januari sampai April 2016. Tempat penelitian dilaksanakan di sekolah yang dekat dengan lubuk larangan desa Tambangan Jae kecamatan Tambangan kabupaten Madina, yaitu SMA Negeri 1 Tambangan, SMP Negeri 1 Laru Tambangan, SD Negeri 147 Laru Tambangan, dan sekolah yang jauh dari lokasi lubuk larangan, yaitu SMA Negeri 1 Panyabungan, SMP Islamiyah Panyabungan, SD Muhammadiyah Panyabungan.

Populasi dalam penelitian ini adalah masyarakat dewasa di desa Tambangan Jae dan siswa SMA Negeri 1 Tambangan, SMP Negeri 1 Laru Tambangan, SD Negeri 147 Laru Tambangan, dan sekolah yang jauh dari lokasi lubuk larangan, yaitu SMA Negeri 1 Panyabungan, SMP Islamiyah Panyabungan, dan SD Muhammadiyah Panyabungan. Pengambilan sampel dalam penelitian ini dilakukan dengan menggunakan teknik Random Sampling, yang mana sampel dalam penelitian ini adalah siswa kelas XII, IX,VI masingmasing 1 kelas setiap sekolah.

Adapun jenis-jenis dengan sumber data yang digunakan dalam penelitian ini dibagi menjadi dua macam, yaitu sumber data primer dan sumber data sekunder. Sumber data primer dalam penelitian ini merupakan data yang diperoleh dari informan yaitu orang yang berpengaruh dalam proses perolehan data atau bisa disebut key member yang memegang kunci sumber data penelitian ini, karena informan benar-benar tahu dan terlibat dalam kegiatan yang ada di lubuk larangan kecamatan Tambangan. Adapun yang menjadi informan dalam penelitian ini antara lain : Kepala Desa dan panitia lubuk larangan yaitu naposo nauli bulung. Sumber data dalam penelitian adalah subjek dari mana data dapat diperoleh. Dalam penelitian ini, peneliti menggunakan kuesioner atau angket dalam pengumpulan data, maka sumber data disebut responden, yaitu orang yang merespon atau menjawab pertanyaanpertanyaan peneliti, baik pertanyaan lisan maupun tulisan. Selain dari angket, peneliti juga menggunakan teknik observasi dan dokumentasi sebagai sumber data.

Adapun dalam pengumpulan data, peneliti melakukan wawancara bersama antara lain dengan Kepala Desa dan panitia lubuk larangan yaitu naposo nauli bulung, serta msyarakat kecamatanTambangan . Hal demikian dilakukan dengan tujuan untuk memeproleh data secara luas dan menyeluruh sesuai dengan kondisi saat ini. Observasi langsung yang dilakukan oleh peneliti bisa direalisasikan dengan cara mencatat berupa informasi dan mengamati bagaimana proses kerja panitia lubuk larangan dalam menjalankan strategi. Dengan observasi secara langsung, peneliti dapat memahami konteks data dalam berbagai situasi, maksudnya dapat memperoleh pandangan secara menyeluruh. Untuk itu peneliti dapat melakukan pengamatan secara langsung dalam mendapatkan bukti yang terkait dengan objek penelitian.

Data yang diperlukan dalam penelitian disesuaikan dengan rumusan permasalahan dan tujuan penelitian. Pengumpulan data dilakukan dengan metode survey menggunakan Angket.Untuk mengetahui tingkat kecenderungan masing-masing komponen dilakukan dengan mengkategorisasikan tingkat pengetahuan siswa. Untuk itu kita dapat mengetahui dari data-data angket yang sudah dikelompokkan dan didepenisikan. Pada kesempatan ini analisis sikap peduli lingkungan tidak dipublikasi.

\section{HASIL DAN PEMBASAN}

\section{Tingkat Pendidikan Siswa dan Masyarakat terhadap Tingkat Pengetahuan Lingkungan}

Dari penelitian yang telah dilakukan mulai dari siswa SMA ( $\mathrm{N}=51)$, SMP $(\mathrm{N}=52), \quad \mathrm{SD} \quad(\mathrm{N}=55) \quad$ serta masyarakat 
$(\mathrm{N}=50)$ total keseluran sampelnya $(\mathrm{N}=$ 208). Maka tingkat pengetahuan lingkungan siswa serta masyarakat di Kabupaten Madina di sekolah yang dekat dan jauh dari lokasi lubuk larangan diperoleh nilai pengetahuan 11 - 42 dari skor 1 - 43; dengan nilai mean 31,14; simpangan baku 6,297 .

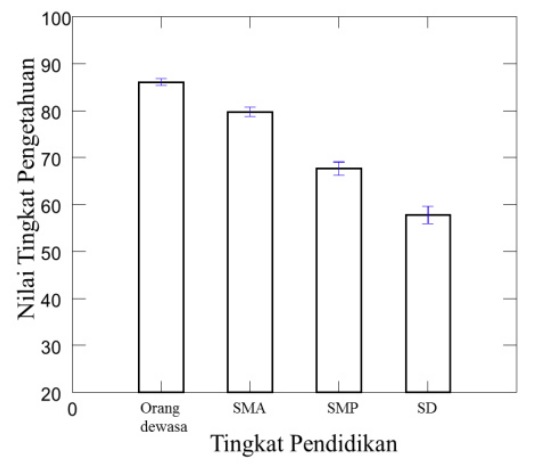

Gambar 1. Nilai pengetahuan lingkungan berdasarkan tingkat pendidikan.

Pada hasil penelitian ini menunjukkan bahwa tingkat pendidikan masyarakat mulai dari orang dewasa, siswa SMA, SMP dan SD secara signifikan berpengaruh terhadap tingkat pengetahuan siswa, dimana tingkat pendidikan yang memiliki rata-rata tertinggi yaitu pada orang dewasa disusul siswa SMA kemudian SMP dan yang paling rendah pada siswa SD.

\section{Lokasi sekolah dengan lubuk larangan terhadap pengetahuan lingkungan}

Pengetahuan siswa yang berlokasi dekat $(\mathrm{N}=80)$ dan jauh dari lubuk larangan $(\mathrm{N}=78)$ total keseluruhan sampelnya $(\mathrm{N}=$ 158) dengan mean 29,28; simpangan baku 6,03 .

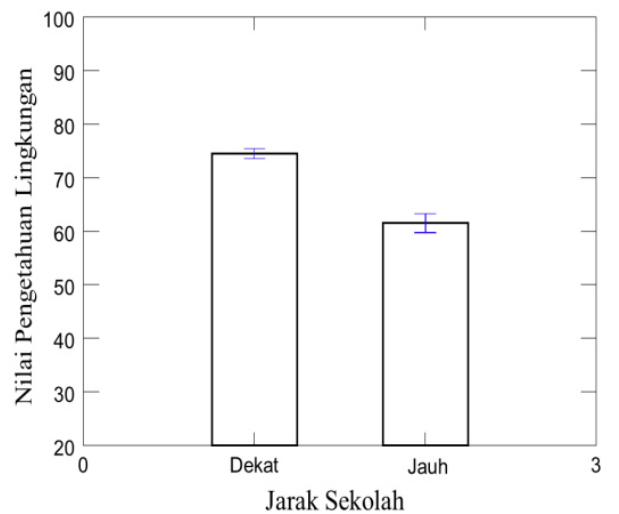

Gambar 2. Nilai pengetahuan lingkungan siswa berdasarkan lokasi sekolah.
Lokasi sekolah yang berada dekat dan jauh dari lubuk larangan secara signifikan berpengaruh terhadap tingkat pengetahuan siswa, dimana lokasi sekolah yang memiliki rata-rata tertinggi adalah di sekolah yang berlokasi dekat dengan lubuk larangan. Lokasi sekolah merupakan tempat mencari dan menemukan ilmu pengetahuan bagi siswa dan di lokasi sekolah ini juga siswa akan berinteraksi dengan lingkungannya sekitarnya sebagai salah satu upaya penunjang siswa untuk belajar di sekolah.

\section{Tingkat pendidikan siswa dan mayarakat terhadap sikap peduli lingkungan}

Analisis tingkat pendidikan terhadap sikap peduli lingkungan siswa SMA, SMP dan SD serta masyarakat tehadap ekosistem sungai berbasis kearifan lokal $(\mathrm{N}=208)$ di Kabupaten Madina diperoleh nilai sikap 4 19 dari skor 1 - 20; dengan nilai mean 12,625; simpangan baku 3,5717. Dalam hal penelitian ini terlihat dari rata-rata skor sikap peduli lingkungan siswa paling tinggi didapatkan dari orang dewasa (masyarakat), kemudian siswa SMA, tetapi bertolak belakang dengan sikap peduli lingkungan antara siswa SD dan SMP, siswa SD memiliki rata-rata skor sikap peduli lingkungannya lebih tinggi dibanding siswa SMP.

\section{SIMPULAN}

Tingkat Pendidikan memberi pengaruh terhadap tingkat pengetahuan tentang lingkungan hidup siswa berbasis kearifan lokal lubuk larangan di desa Tambangan Jae kecamatan Tambangan kabupaten Madina. Rata-rata pengetahuan orang dewasa lebih tinggi lebih tinggi dibandingkan siswa SMA, SMP, dan SD. Lokasi sekolah dengan lubuk larangan memberi pengaruh terhadap tingkat pengetahuan tentang lingkungan siswa berbasis kearifan lokal lubuk larangan.Ratarata pengetahuan siswa yang sekolah dekat dengan lubuk larangan lebih tinggi dibanding dengan siswa yang sekolahnya jauh dari lubuk larangan. 


\section{DAFTAR PUSTAKA}

Abdillah, P. 2007. Kamus Lengkap Bahasa Indonesia. Surabaya: Arkola.

Amry,F \& Saam, Z \& Thamrin. 2013. Kearifan Lokal Lubuk Larangan Sebagai Upaya Pelestarian Sumberdaya Perairan di Desa Pangkalan Indarung Kabupaten Kuantan Singingi.Pusat Penelitian Lingkungan Hidup Universitas Riau 1 (1):36-43.

Basya,H.S.2010. Cara Jitu Mendidik Anak Soleh dan Unggul di Sekolah. Jakarta: Zikrul Hakim.

Badan Perencanaan dan Pembangunan Daerah. 2014. Kecamatan Tambangan dalam Angka 2014. Laru Lombang: Kantor Camat Tambangan.

Badan Pusat Statistik Kab. Mandailing Natal.2013. Kecamatan Tambangan : kantor camat Tambangan.

Budiyono.2011.Pengelolaan Lubuk Larangan Sebagai Bentuk Kearifan Lokal di Kabupaten Bungo. (http://budibungo-pengelolaan- lubuk-larangan.html. diakses 1 September 2015).

Convello \& Cevilla. 1993. Pengantar Metode Penelitian. Jakarta : Universitas Indonesia.

Depdiknas.2006.Model Mata Pelajaran Muatan Lokal.Departemen Pendidikan Nasional.Jakarta.

Feranita, F.M.2008. Metode Sampling Bioekologi.Jakarta : Bumi Aksara.

Gomez-Baggethun, E \& Corbera,E \& ReyesGarcía, V. 2013. Traditional ecological knowledge and global environmental change: research findings and policy implications. Ecology and Society 18(4): 72

Hadi,S.1997. Metode Research. Yogyakarta: Fakultas Psikologi UGM

Hasibuan, U \& Suwondo \& Fauziah,Y. 2015. Analysis Of The Management Of Lokal Wisdom Lubuk Larangan Of River Kaiti For Development Of Module Concept The Evviromental Conzervation In Senoir High School.Kajian Lingkungan. 1(1):1-15.

Hak, A \& Rifardi \& Siregar,I.Y. 2013. Kajian Kapasitas Asimilasi Perairan Sungai Rokan Desa Rantau Bais Kabupaten Rokan Hilir Propinsi Riau Jurnal Kajian Lingkungan Universitas Riau.1(1):1-15.

Imam, S \& Tobroni. 2011. Metode Penelitian sosial Agama. Bandung: Remaja Rosdakarya.

Iskandar, A. 2003. Budidaya Ikan Nila Merah (Oreochromis, Sp). Karya Putra Darawati. Bandung.
Lexy,J \& Moleong. 1998. Metode Penelitian Kualitatif. Bandung: Remaja Rosdakarya.

Mardalis.1997. Metode Penelitian Suatu Pendekatan Proposal.Jakarta:Bumi Aksara.

Mulyanto, H. R. 2007. Sungai, Fungsi dan Sifat-Sifatnya. Yogyakarta: Graha Ilmu.

Meliono, I . 2011.Under Standing the Nusantara Thought and Lokal Wisdom as an Aspect of The Indonesian Education. International Journal of Historycal Studies,2 (2) : 221234.

Nasution, S. 2006. Metode Research. Jakarta :Bumi aksara.

Parwati, A \& Purnaweny, H \& Anggoro. D. D. 2012. Nilai Pelestarian Lingkungan Dalam Kearifan Lokal Lubuk Larangan Ngalau Agung Di Kampung Surau Kabupaten Dharmasyara. Provinsi Sumatra Barat.Pengelolaan Sumberdaya Alam dan Lingkungan:98-102.

Poerwanto,H. (2008). Kebudayaan dan Lingkungan dalam Perspektif Antropologi. Yogyakarta: Pustaka Pelajar.

Sudarto.2005. Metodologi Penelitian Filsafat. Jakarta:Grafindo Persada.

Singarimbun,M \& Efendi,S.1989.Metode Penelitian Survei.Jakarta:LP3S.

Soeratno .1995. Metodologi Penelitian. Yogyakarta:UUP AMP YKPN.

Suwondo, Elya Febrita, Mahmud Alpusari. 2004. Kualitas Biologi Perairan Sungai Senapelan, Sago dan Sail di kota Pekanbaru Berdasarkan Bioindikator Plankton dan Bentos. Jurnal Biogenesis 1(1): 15-20.

Suhana.2008.Pengakuan Keberadaan Kearifan Lokal Lubuk Larangan Indarung Kabubapaten Kuantan Singingi Provinsi Riau dalm Pengelolaan dan Perlindungan Lingkungan Hidup.Commit Center For Ocean Development and Maritime Civilization Studies:1-8.

Suwondo, 2004. Kualitas Biologi Sungai Senapela,Sago,Dan Sail Di Kota Pekanbaru Berdasarkan Bioindikator Plankton Dan Bentos: FMIPA FKIP,Universitas Riau Pekanbaru.

Sutrisno, H. 1987. Metodologi Research. Yogyakarta: Fak Psikologi UGM

Tambunan, RQ \& Laman. 2015. To Manage Of Lubuk Larangan As A Enviromental Wisdom In Salambue Village Panyabungan Kota Subdistrict Mandailing Natal Regency North Sumatra Province. Pusat Penelitian Lingkungan Hidup Universitas Riau. 2(1):17). 